\title{
Improving Communication between Postgraduate Researchers and the University Library: A Case Study at De Montfort University Library and Learning Services
}

\author{
Melanie Petch ${ }^{\mathrm{a}}$, Katie Fraser ${ }^{\mathrm{b}}$, Nathan Rush ${ }^{\mathrm{a}}$, Alan Cope ${ }^{\mathrm{a}}$, and Julie Lowe ${ }^{\mathrm{a}}$ \\ a Library and Learning Services, De Montfort University, Leicester, UK \\ ${ }^{b}$ Libraries, Research and Learning Resources, University of Nottingham, Nottingham, UK
}

\begin{abstract}
A well-established postgraduate researcher development program has existed at De Montfort University for many years. Library and Learning Services include modules on literature searching skills and critical appraisal. However, we recognized that researchers seemed to be disengaged with the services on offer. This concern informed a research project that considered the ways we could communicate better with researchers based on their needs. This paper explores the essential components of successful communication, such as context, timeliness and communication channels. An action-research approach was taken including focus groups and online surveys. The outcomes highlighted three significant crisis points, emphasizing the key times when researchers might need some intervention. The findings of this research identified the distinct needs of Postgraduate Researchers (PGRs) and how relevant and timely communication from the library can meet these needs. It also considers the impact of how communication has improved with researchers as a result of some of our interventions.
\end{abstract}

\section{Keywords}

communication; doctoral research; academic libraries

\section{Introduction}

Silver (2014) has recognized the need to augment perceptions of academic libraries by working with users as a means of "understanding their needs and practices, and establishing collaborative partnerships that serve to empower student learners and enhance scholarly productivity" (p. 9). Silver's perspective provides a useful mantra to define a two-year project that has involved a team of librarians and learning developers at De Montfort University (DMU). The focus of the project has been to review the way Library and Learning Services (LLS) communicates with Postgraduate Researchers (PGRs). DMU, Leicester, is a large "post 1992" university with over 16,000 undergraduate and postgraduate students. The number of PGRs has grown in recent years, currently with 700-750 PGRs enrolled. DMU offers researcher development support through its Graduate School Office, Research, Business, and Innovation Department and via faculty-based doctoral training programs. Collaborating with these partners, a well-established development program for PGRs has existed in the library for many years, including a compulsory module on Literature Searching skills, and an optional module on Critical Approaches to Research. Despite receiving positive feedback from PGRs, attendance was often poor at these sessions, making it difficult for us 
to justify the continuation of such programs: an experience which seems to hold for other institutions (Bussell, Hagman, \& Guder, 2015). This lack of engagement seemed to imply that PGRs did not perceive LLS as a key touch point for their development as researchers.

An opportunity was offered in 2013 , via internal funding, to review our communication strategy and to improve the levels of engagement LLS had with PGRs. To help us do this, we took an actionresearch approach (Costello, 2003) to better understand how PGRs viewed and understood communication from LLS, and how significant our provision was against the backdrop of their research. Drawing upon phenomenological influences, we ran a series of focus groups with PGRs to understand the perspective from "inside" the PhD. We then thematized some of the major challenges that our PGRs had encountered (Howitt \& Cramer, 2011).

This article offers an overview of the literature surrounding communication and an outline of how we coordinated our focus groups. It also presents our findings as a sequence of three crisis points that PGRs identified as integral to their research process. They have provided us with rich insight into how and when LLS communication needs to be more meaningful, timely, and reciprocal as well as how it can benefit from the active involvement of supervisors. We finish the article by documenting the changes we have since made to our communication strategy, and present the results of a recent questionnaire that invited PGRs to review the effectiveness of our communication two years' on.

\section{Reviewing the literature on communication}

There is a noticeable absence of existing literature that focuses explicitly on the communication between libraries or learning development and the PGR community. However, some studies show a need for improved communication (Rempel, Hussong-Christian, \& Mellinger, 2011; Sadler \& Given, 2007). Fleming-May and Yuro (2009) further note that we might expect well-documented difficulties in communications between libraries and academic staff to begin during doctoral study. We have, therefore, reviewed the literature to see what lessons could be learnt about good communication between PGRs and libraries (usually in the context of skills development, see Catalano (2013) for an overview). We have further considered this alongside studies on communication between PGRs and other stakeholders such as supervisors.

\section{Meaningful communication}

There are several levels at which mismatches in communication might exist between LLS and PGRs. The first is at a broad philosophical level. Molesworth, Nixon, and Scullion (2009) allude to the marketization of higher education in the United Kingdom, stating that "students seek to "have a degree' rather than 'be learners"' (p. 278). This marketization results in students wanting tangible outcomes: they are not interested in the pedagogical theories that have previously underpinned higher education teaching. "Library" teaching may have to be refocused to take account of this shift. This sets us with a new challenge of being more pro-active but also receptive to feedback on the nature of our advocacy.

There is already evidence that the specific educational goals of libraries may lack resonance for PGRs. In Sadler and Given's (2007) study of eight graduate students' behavior, their relationship with library information literacy was paramount for librarians "who viewed it as their primary channel of communication with students" (p. 131). Studied by structured interviews and task-based computer explorations, it was noted the students placed information literacy programs low on their list of priorities with the consequence that communication was not taking place. This gives weight to an argument that communications may need to focus on more tangible outcomes for the student. 


\section{Timely communication}

Timeliness might be a key factor in ensuring that a message is received as intended. Pettersson (2002) states, "Information is only useful at exactly the time we need it. Thus, when we have access to information is an important factor" (p. 42). The PhD process is often documented as a series of stages (Phillips \& Pugh, 2000), suggesting that communications with PGRs in this process could be easily targeted. However, accompanying narratives suggest that these accounts are misleading. Brydon and Fleming (2011) found that some researchers embark on their PhDs with the perception that the process is straightforward and linear and falls into "neat, sequential categories" while the reality is "akin to a long journey fraught with twists and turns, with few defined signposts and the need to constantly adapt to unexpected events" (p. 996). Targeted communications therefore need to be sensitive to the complexity of the process and how it may be different for each PGR.

Nonetheless, key points in the PhD process have been identified where communication might be valued. There is particular lassitude at the midway point in the research process (Phillips \& Pugh, 2000). This represents the transition between the two most active phases of the PhD process and is often characterized by lethargy and despondency. The developmental focus of LLS could therefore be a good way to re-energize students at this crucial stage and help them to avoid the feeling of isolation.

\section{Two-way communication}

There has been some theoretical agreement (Dimbleby \& Burton, 1998; McQuail, 1975) that communication is a sharing process. Feedback, therefore, can be integral to the communication process. A 2005 audit of executive communication, surveying CEOs (Gray \& Robertson, 2005) concluded that where there is no feedback, there is no communication; "communication is about the creation of meaning and understanding, not simply moving information around" (p. 27). Similarly, Denis McQuail states that a communication event only occurs when feedback has been received, and when some activity has occurred as a result of the communication. In a marketing context, Smith and Taylor (2002) point out that if the PGR chooses to ignore the message then no communication will take place; an understanding of the receiver is required to mitigate this happening.

There is clearly a need for greater feedback from PGRs, but there is acknowledgement in the literature that obtaining feedback can be extremely difficult, particularly in mass communications (Copley, 2004). Much of the communication attempted by LLS takes this form: messages are transmitted, but the only "feedback" may be a lack of engagement with the communication offered. Yet, even in the context of Web 2.0, which is designed for two way communication, libraries often seem to neglect this opportunity; so concluded Gerolimos (2011) in an analysis of 20 randomly selected US academic library Facebook pages.

\section{Meaningful communicators}

Lastly, perhaps the best way to ensure that messages about library and learning development is both meaningful and timely is to have it come from someone closer to the PhD process itself. Brydon and Fleming (2011) drawing on their own experiences of conducting a PhD, recognize the importance the supervisor plays in the PhD process. Mewburn (2011), in a literature review on researcher education, documents some PGRs' innate desire for a "mothering" or "coaching" figure. Librarians and learning developers rarely build up this kind of one-to-one relationship with students. Furthermore, the supervisor is probably best placed to identify what kind of help will be most useful to the student, and when.

What about the influence of other PGRs? There is relatively little research on peer interaction amongst graduate students compared with the wealth of study of undergraduate peer mentoring schemes (Terrion, 2012). However, there is some evidence that PGRs like to work together. A study by Majid (2009) found that two thirds of 200 graduate students surveyed preferred team projects 
over individual assignments. The downsides of arranging this were pragmatic rather than educational: time constraints, availability of the group, and cultural differences. Furthermore, Fleming-May and Yuro (2009) in a focus group study of 24 social sciences doctoral students found that students were more comfortable asking their peers for advice than either academics or librarians. However, arranging a group of genuine "peers" may be difficult as the PGR journey is diverse; such a contention was found through interviews and discussions with education researchers (Boud \& Lee, 2005).

\section{Methods}

\section{Part 1: Focus groups and initial questionnaire}

To gain a better understanding of how Library and Learning Services communicates with doctoral researchers the team designed an action research project (Costello, 2003). The aim was to use a thematic analysis with a phenomenological influence (Howitt \& Cramer, 2011) to better understand how researchers in the process of their PhD viewed and understood communication from the service. A phenomenological approach was chosen because although the project team were professional staff who had worked with researchers for many years (and, in some cases, had undertaken doctoral study), it was recognized that the local perspective from "inside" the PhD was likely to be very different. Furthermore, this perspective would significantly affect the meaning of communications that the researchers received.

Although focus groups are not commonly used in a phenomenological approach, in this case they allowed the researchers to build a collaborative model of the similarities and differences of PGRs' own experiences. Two focus groups, each consisting of six PGRs, were recruited by e-mailing PGRs and their supervisors. Researchers were included from different faculties, those studying locally and overseas, and international and UK researchers. The intention was to run four groups, but perhaps unsurprisingly we faced similar recruitment challenges to those we had encountered in persuading PGRs to attend our training. Attendees were thanked with a free lunch.

All researchers in the focus groups were asked to sign a consent form on arrival, and it was explained that the sessions would be recorded and transcriptions anonymized.

To compare the findings with others who were unable to attend the groups, the team designed an online questionnaire. This facility also captured the voices and opinions of overseas researchers and UK researchers who were unable to travel to Leicester. Again, the response rate was low: 10 of approximately 400 PGRs total (under 3\%). However, the data gathered did seem to suggest that the focus groups reflected a shared experience that generalized beyond those who were able to attend.

The focus groups produced a number of artifacts that were the subject of the phenomenological analysis: recordings of the focus groups, which were transcribed; timelines of the PGRs' degrees; and sorted index cards with key points of communication. These artifacts were supplemented by freehand responses from the questionnaire. A thematic analysis was used to pick up key ideas from this data.

\section{Part 2: Follow-up questionnaire}

The follow-up questionnaire was distributed in November 2015, and asked PGRs about their experience of and confidence in communicating with LLS. This time, 16 of approximately 700 PGRs replied (again, under 3\%). Although we were not able to compare the PGRs' experience of our communication directly before and after the changes, the questionnaire specifically focused on aspects of our communication that the initial study suggested needed review. The focus group schedule and both initial and follow-up questionnaires can be accessed at http://hdl.handle.net/2086/11373. The results of the questionnaire can also be viewed in online supplemental material. 


\section{Distinctive researcher identity}

A key theme to emerge was the importance to the PGRs of being perceived by the academic community, and the university itself, as genuine researchers. According to PGRs, this could be achieved in a number of different ways. For one participant, validation of a researcher identity was very much concerned with physical space and the perceived status researchers from other institutions are given if they have their own office space: "Sometimes when you meet other researchers from other universities you are envious." For another participant, it was more about opportunities to participate in the research community, reflecting the serious attitude PGRs often assume when they begin their work. This is consistent with other work looking at PGR identity (Mantai, 2015).

Another interesting aspect relating to researcher identity is the need for PGRs to be treated as researchers rather than simply in the same way as undergraduates. One participant noted that there was a need to "Differentiate between undergraduate and postgraduate services." This suggests that researchers expect a degree of recognition in terms of the distinctiveness of their experience as a researcher. Another participant stated that, unlike undergraduates, PGRs are rarely asked for feedback. This was at least partly an issue of perception: participants in the same group were unaware of the Postgraduate Research Experience Survey (Higher Education Academy, 2015). However, it does also emphasize the importance of giving PGRs the chance to feedback regularly to all the university's services.

At formal LLS help-points such as enquiry desks the focus is on offering practical information on request. However, it is clear to see from the feedback by focus group participants (especially international students) that the journey to Leicester to begin their PhDs is a tiring and emotional one. It seems that LLS colleagues may be inadvertently failing to acknowledge this journey. One easy step would be to develop resources and promotional material that uses researcher discourse; one that speaks the language of researchers. This approach applies to both face-to-face and remote interactions with PGRs. Furthermore, simple recognition that studying for a PhD can be isolating and intense might demonstrate better understanding of their circumstances and better support PGRs in their development.

\section{Communities of support}

Both the focus groups and the initial questionnaire identified a sense of community as being a really significant aspect of the researcher experience. A number of participants praised the researcher development training they received from the Graduate School Office for its approach to bringing students together, indicating that it "makes [students] feel part of the culture."

Although the training was seen as a major way of meeting other PhD students, some felt that it did not go far enough in establishing a relevant community of their peers, with one commenting: "It is quite good to meet students from other faculties as well. But I felt you meet them then, but you may never see them again... you still feel quite disconnected." Clearly there is potential for more opportunities to nurture these early friendships and alliances. PGRs seem to want to embark on a journey together; starting in the same place and working through the experience as a team.

What does this mean for LLS? The PhD student writing group and the interactive elements in the Researcher Development Program already offered by the directorate were mentioned as examples of good practice in the groups, but there are further opportunities to nurture communities of support. Potential options include factoring in more time for peer activities during training sessions, giving the space to develop friendships and to interact. There might also be ways of providing training days closely timed with other sessions on the RDP, or with writing group activities, so that the PGRs can form a cohort. 
Of course, the sense of a community also needs to extend to distance learners. One way to achieve this would be to provide avenues for online discussion. There has been extensive discussion of the roles of "communities of practice" in building and sharing research student experiences along these lines (e.g., Wisker, Robinson, \& Shacham, 2007). However, it should be noted that these types of community may lack authenticity if attempts are made to construct them from outside, rather than allowing them to emerge (Schwen \& Hara, 2003). Starting with an existing "community" like the writing group might be a good way to carry this forward, and the directorate could also investigate the opportunity to collaborative with other services on extending existing networks to an online format.

\section{PGRs' perceptions of provision}

The issue of how relevant participants in our focus groups and survey saw library provision presents a rather conflicted picture. Some PGRs were very positive. Some had been skeptical about attending training but were won over "I've got to sit through this for three hours? But it was useful... I think it was because it was quite interactive." The implication here is that communication could be more successful, despite high satisfaction levels.

However, other comments suggest that the service was not particularly meaningful to some individuals. In the initial questionnaire responses one respondent felt that "The library needs to be seen as an additional resource," implying that it was not seen as one already. Another had mixed experiences with their subject librarians, suggesting that they are not aware of everything on offer: subject librarian help is often offered remotely by e-mail or by phone. There is an assumption made that librarians' support is limited. It was not clear from either the focus groups or the initial questionnaire to what extent PGRs had actual contact with their librarians, or whether they were making assumptions about services based on the information that was most visible.

One respondent to the initial questionnaire suggested "More profiles needed for subject librarians." This tends to suggest that while PGRs are curious in what the library has to offer, the information available does not fully communicate the relevance of the provision and particularly the relevance of the librarian to their research. A "profile" might contain a variety of information. This PGR could be asking for a simple indication as to what support any librarian could offer, or suggesting that librarians need to be presented as fully-rounded individuals. Certainly, for such a profile to capture PGRs' interest it would need to indicate the relevance of the librarians to researchers, perhaps even emphasizing librarians' own research experience.

A different communicator might increase the relevance of the message to students, as we saw in the work of Brydon and Fleming (2011). When prioritizing the key "communicators" the PGRs in our project placed the supervisor as the most important point of communication, with the Graduate School also ranked highly. This suggests that the supervisor and Graduate School are important partners for Library and Learning Services in supporting PGRs. Nonetheless, Library and Learning Services provision was also ranked in the top end of the list in terms of importance (despite reassurance from the facilitators that no offence would be taken if it was ranked in a low position). This suggests that direct messages from LLS would be valued highly by at least some PGRs.

\section{Clarity and consistency of provision}

Another theme that arose was a lack of clarity and consistency in the practice of LLS. The participants in our study were clear that what was on offer needed to be lucid; participants noted that LLS provision can be "a bit confusing," to the extent where they "cannot find support." Similarly, it needs to be persistent: with one student professing to "need reminding [about the library]."

Information about LLS was delivered through a variety of points. In the focus group, initial contacts mentioned by participants included visiting the service website, attending formal inductions, meeting subject librarians and visiting library buildings. Feedback suggested that all these elements had room for improvement. For example, when asked whether the library was a welcoming place, 
one participant noted: "Sometimes yes sometimes no - depends on the individual," and, as discussed under the umbrella of perceived relevance, the subject librarians were seen as very helpful by some, and irrelevant by others.

There were several comments on LLS's online presence. In one focus group, participants queried where they found information on the writing group. They were unsure, despite the fact that some information on timing and content is available online. Further comments were made about improving LLS's online presence, suggesting that the pertinent webpages need to be reviewed to ensure information relevant to research students is visible and retrievable.

Furthermore, several participants stressed the need for regular contact: an email, or a monthly newsletter, were mentioned as being the preferred form for doing this: "Email me! Email!" they said. This is consistent with the idea seen in the literature that human contact (as far as possible) is preferred (Sadler \& Given, 2007). However, it seems library staff needs to be more proactive in promotion of its provision to PGRs: possibly by being more persistent with their modes of electronic communication.

\section{Timing of provision}

In the focus groups, participants mapped out a timeline of their communication with other key agents in the research process. Although the timelines created by the PGRs in both focus groups looked rather different, they shared several properties. The first was in the structure of the PhD. This contained several milestones for their key agents, all front-loaded toward the start of the PhD process, although further milestones were mentioned.

The second element was the activities they were involved in. Participants clearly identified stages in their research as suggested by Phillips and Pugh (2000). It was evident that at least some of the participants had experienced, or were aware that the research process is not a neat linear process but a potentially contorted journey (Brydon \& Fleming, 2011). However, some PGRs presented discrete elements of activity, such as the completion of the literature review, data collection, and writing up period.

The collated timeline shown in Figure 1 was created by synthesizing the milestones, stakeholders, and activities discussed by the PGRs in the two focus groups. 
Figure 1. This collated timeline was created by synthesizing the milestones, stakeholders, and activities discussed by the PGRs in the two focus groups.

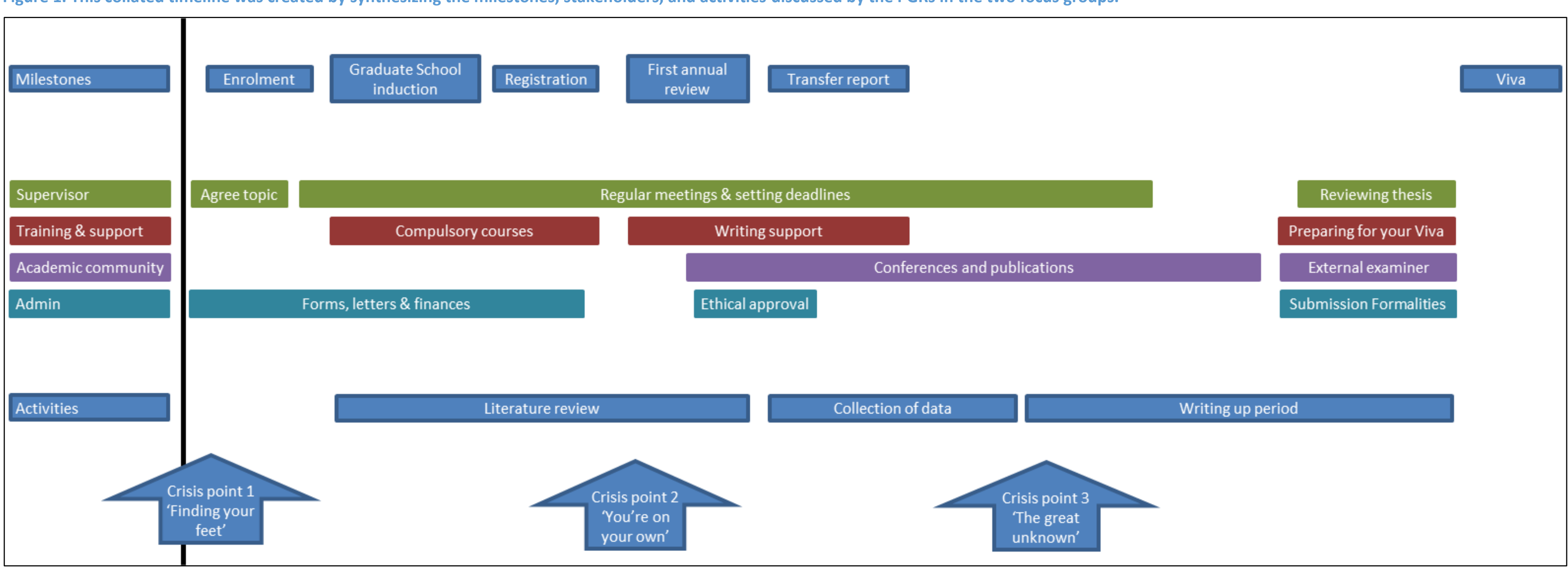


There were four main types of communication PGRs marked throughout their PhD timeline:

\section{Supervisor}

Contact with the supervisor was presented consistently throughout the timeline, perhaps trailing off a little at the end. It was unclear whether this reflects reality, or just the fact that most PGRs had not arrived at this stage and did not know what to expect.

\section{Training and support}

Again, training and support (outside the supervisor relationship) was front-loaded toward the start of the PhD. This seems to more closely reflect reality, especially in terms of LLS provision and support.

\section{Academic community}

The wider academic community, however, was seen as something PGRs reached out to later in the $\mathrm{PhD}$ process. Starting this process early seemed to be a sign of confidence in one's place in the academic world.

\section{Admin}

Some tasks were referred to students in terms of an administrative burden. These were tasks that could be more or less integral to the PhD, but were presented as administrative boxes that needed to be ticked in the context of the timeline. ${ }^{1}$

When talking through the timeline, PGRs indicated "crisis points" where there seemed to be some shared concerns about the PhD process.

\section{Crisis Point 1: "Finding your feet"}

The period before enrolment was considered to be an important stage in the research process, and the first crisis point was around the time of enrolment, as PGRs were finding their feet. They had not started the core training courses yet, but were involved in processing considerable amounts of paperwork and agreeing their topic with their supervisor.

The timelines indicated that PGRs' first formal contact with LLS was often at induction. In some cases this was attended up to six months after enrolment, so some PGRs had not experienced a formal introduction during the important early months of their research. This suggests that there is a real disjuncture between what researchers need and what LLS staff provide in terms of an initial welcome.

However, the late timing of official introductions did not mean that PGRs were unaware of some elements of the service. One focus group participant recalled how on: "My first day the supervisor said 'make the library your second home if you want to make progress'." This demonstrates how the library is often prioritized as a key base for research. Many other participants indicated that they had been encouraged to engage with the "the library" and its resources at an early stage. In terms of communicating with researchers, this is a rich opportunity and it appears that LLS may be missing the most receptive stages in the researchers' experience.

\section{Crisis Point 2: "You're on your own"}

The second crisis point was the stage after registration and before the annual review. At this stage PGRs had often completed large amounts of the compulsory training courses and were moving into an area where they had less structure.

\footnotetext{
${ }^{1}$ Ethical consent is an example here of an activity that clearly has a strong relationship to the topic but was presented as a "check box" task in that it needs to be completed before a stage of the project could progress.
} 
For many participants, this stage in the PhD process was isolating and often directionless. One participant noted that: "After registration if one is not careful you can become disappointed ... no one is there to show you what to do next." Other participants noted the "individuality" and "isolation" of their research after this point. It may be that clear signposting to resources and indeed the $\mathrm{PhD}$ process itself is no longer required past a certain stage. This second crisis point has also been acknowledged by Phillips and Pugh (2000) highlighting the lethargy researchers can feel at this stage in their research.

\section{Crisis Point 3: "The great unknown"}

The third crisis point - the writing up period-was also identified as being a potentially difficult stage, although most of the participants had not reached it yet. A number of training courses were anticipated to support PGRs through the Viva, but they seemed to anticipate very little support in completing the production of their thesis. One PGR even commented "You're on your own!"

PGRs particularly anticipated problems particularly with the formats and conventions for academic writing when referring to the writing up stage, with the timeline reflecting the lack of formal support during this time.

At the second crisis point many participants in the focus group had experienced a sense of isolation; at the third crisis point, they were expecting it. This shared theme of isolation indicates a strong relationship between these crisis points and the need for a community of support identified by the PGRs in the group more generally.

\section{Moving forward}

These results have had a significant impact on the way we now structure our researcher development in the library. In particular, our communication with PGRs has seen a number of new approaches since 2013. In detail, we have:

- Adapted our induction slides to demonstrate how LLS provision "speaks" to the PGR crisis points.

- Increased the number of opportunities for community among PGRs by introducing monthly Thesis Drop Ins, "Elevenses" information-sharing, the continuation of the Writing Group for Research Students and the coordination of an Open Research Conference due to be held in May 2016.

- Developed a training course focusing on some of the identity issues and crisis points faced by PGRs called: "What does it mean to be a PGR?" The course was launched in December 2015.

- Developed an online Researchers Guide that outlines library and learning development in one place.

- Improved liaison with supervisors by offering an introduction to LLS support on the Certificate in Research Supervision.

- Developed paper-based promotional resources that provide a cohesive account of PGR support between both library colleagues and learning developers.

- Plans to embed our events and training opportunities via an online journey tool called My

Research, which will enable PGRs to track opportunities available to them in LLS.

We recognize that there is scope to present these initiatives in more detail, and hope to outline the effectiveness of these separate activities through further research.

\section{Current communication with PGRs}

In order to evaluate the effectiveness of our communication with PGRs two years' on, we conducted a follow-up questionnaire to identify their levels of satisfaction. The results showed that: 
- The range of provision on offer was perceived very satisfactorily by $75 \%$ of PGRs. (No PGRs said the provision was "not relevant at all.")

- In terms of modes of communication, our survey indicated that while most modes of communication were clear or fairly clear, two students did indicate that the library webpages and contact within library spaces still needed more clarity.

- It was pleasing that $93.7 \%$ of respondents felt that LLS met their needs at varying points of their research, indicating that LLS had noted the identified crisis points and responded accordingly.

- It was also noteworthy that $100 \%$ of the respondents were very or fairly confident in how to contact the Library when they needed support.

\section{Conclusions}

The aim of this article was to present what we have learned about PGRs to embed a more effective communication strategy within LLS and to better understand and improve communications with PGRs. In pursuing this goal, a large amount of information was captured about the inside experience of studying for a PhD at De Montfort University. Particular themes which arose in the focus groups, and were corroborated in the initial questionnaire were:

- that research students had distinct needs which could be better reflected in LLS's communications and provision of services, including supporting their identity as researchers, and facilitating communities of support;

- that LLS needed to better convey its relevance to PGRs, and ensure that this group received a clear and consistent message across all aspects of its provision; and

- that precise timing of messages was critical to the receptiveness of PGRs to LLS'S communications, and to the usefulness of its provision.

Together this awareness, and our subsequent re-consideration of how we communicate with PGRs, has led to a better take up of LLS' provision: the team of learning developers has seen a $50 \%$ increase in the number of PGRs accessing its provision in 2014-15. These approaches also present an offer of supplementary support that better reflects PGRs' real experiences, and, as hoped at the start of the project, communication that is both relevant and effective.

\section{Acknowledgments}

We, the authors, confirm that this article has not been published elsewhere and that it has not been submitted simultaneously for publication elsewhere.

\section{References}

Boud, D., \& Lee, A. (2005). "Peer learning" as pedagogic discourse for research education. Studies in Higher Education, 30, 501-516.

Brydon, K., \& Fleming, J. (2011). The journey around my PhD: Pitfalls, insights and diamonds. Social Work Education, 30, 995-1011.

Bussell, H., Hagman, J., \& Guder, C. S. (2015). Mixin' it up: Using a mixed- methods approach to understand graduate research needs. Proceedings of the American College \& Research Libraries Conference (pp. 554-565), Portland, OR, ACRL. Retrieved November 22, 2015, from http://www.ala.org/acrl/sites/ala.org.acrl/files/content/conferences/confsandpreconfs/2015/Bussel I Hagman Guder.pdf 
Catalano, A. (2013). Patterns of graduate students' information seeking behavior: A meta-synthesis of the literature. Journal of Documentation, 69, 243-274.

Copley, P. (2004). Marketing Communications Management: Concepts and theories, cases and practices. Oxford, England: Elsevier Butterworth-Heinemann.

Costello, P. J.M. (2003). Action research. New York, NY: Continuum.

Dimbleby, R., \& Burton, G. (1998). More than words: An introduction to communication (3rd ed.). Abingdon, England: Routledge.

Fleming-May, R., \& Yuro, L. (2009). From student to scholar: The academic library and social sciences PhD students' transformation. Portal: Libraries and the Academy, 9, 199-221.

Gerolimos, M. (2011). Academic libraries on Facebook: An analysis of users' comments. D-Lib Magazine, 17(11/12). Retrieved November 22, 2015, from

http://www.dlib.org/dlib/november11/gerolimos/11gerolimos.html

Gray, R., \& Robertson, L. (2005). Effective internal communication starts at the top. Communication World, 22(4), 26-28.

Higher Education Academy. (2015). Postgraduate research experience survey. Retrieved November 22, 2015, from http://www.heacademy.ac.uk/pres

Howitt, D., \& Cramer, D. (2011). Introduction to research methods in psychology (3rd ed.). Harlow, England: Prentice Hall.

Majid, S. (2009, March). Perceptions of LIS graduate students of peer learning. Asia-Pacific Conference on Library \& Information Education \& Practice, Tsukaba, Japan. Retrieved November 22, 2015, from http://www.slis.tsukuba.ac.jp/aliep2009/proceedings/Papers/a8.pdf

Mantai, L. (2015). Feeling like a researcher: Experiences of early doctoral students in Australia. Studies in Higher Education. doi:10.1080/03075079.2015.1067603

McQuail, D. (1975). Communication. London, UK: Longman.

Mewburn, I. (2011). Troubling talk: Assembling the PhD candidate. Studies in Continuing Education, 33, 321-332.

Molesworth, M., Nixon, E., \& Scullion, R. (2009). Having, being and higher education: The marketisation of the university and the transformation of the student into consumer. Teaching In Higher Education, 14, 277-287.

Pettersson, R. (2002). Information design: An introduction. Philadelphia, PA: John Benjamin. Phillips, E. M., \& Pugh, D. S. (2000). How to get a PhD: A handbook for students and their supervisors. Buckingham, England: Open University Press.

Rempel, H. G., Hussong-Christian, U., \& Mellinger, M. (2011). Graduate student space and service needs: A recommendation for a cross-campus solution. The Journal of Academic Librarianship, 37, 480-487.

Sadler, E., \& Given, L.M. (2007). Affordance theory: A framework for graduate students' information behaviour. Journal of Documentation, 63, 115-141.

Schwen, T. M., \& Hara, N. (2003). Community of practice: A metaphor for online design. The Information Society, 19, 257-270.

Silver, I. D. (2014). Outreach activities for librarian liaisons. Reference \& User Services Quarterly, 54(2), 8-14.

Smith, P. R., \& Taylor, J. (2002). Marketing communications: An integrated approach (3rd ed.). London, UK: Kogan Page. 
Terrion, J. L. (2012). Student peer mentors as a navigational resource in higher education. In S. Fletcher \& C. Mullen (Eds.), Sage handbook of mentoring and coaching in education (pp. 383-396). London, UK: Sage.

Wisker, G., Robinson, G., \& Shacham, M. (2007). Postgraduate research success: Communities of practice involving cohorts, guardian supervisors and online communities. Innovations in Education and Teaching International, 44, 301-320. 